\section{Difusão de Ciências: Um Instrumento para Incluir Socialmente e Despertar Vocações Científicas e Tecnológicas em Jovens de Todo o País}

\author{
Science Dissemination: An Instrument for Socially Including \\ and Awakening Scientific and Technological Vocations in \\ Youth Around the Country
}

RESUMO

Os pesquisadores do Grupo de Óptica do IFSC, na Universidade de São Paulo, vêm realizando intensas atividades de difusão de Ciência desde 2001, por meio de exposições itinerantes, workshops e de feiras de ciências em escolas e espaços públicos. Além disso, gerenciam o canal TV Ciência, 24 horas no ar, e mantêm colunas científicas em rádio, sites e jornais. Por meio dessas mídias são veiculados programas científicos para várias regiões do país. Outra atividade relevante é a organização da Olimpíada Brasileira de Física e da Olimpíada Brasileira de Física das Escolas Públicas, que juntas contaram com a inscrição de 863.402 alunos na primeira fase. No presente trabalho, são abordadas as atividades gerais de difusão do Grupo de Óptica, com destaque ao treinamento dos professores e monitores. Em seus depoimentos os estudantes monitores citam como benefícios dos projetos a ampliação dos seus conhecimentos científicos, além de sensível melhoria na capacidade de oratória em público e da capacidade de organizar eventos e de responder às situações imprevistas. Esperamos que tais ações venham a ampliar o campo de possibilidades que esses jovens terão no mercado de trabalho, além de conceder-lhes uma atitude mais eficaz e positiva frente aos inúmeros desafios da vida.

Palavras-chave: Difusão Científica. Exposição. Olimpíada de Física.

\section{ABSTRACT}

Researchers from the Group of Optics (Institute of Physics - University of São Paulo) have been carrying out intense activities for the dissemination of Science since 2001, through itinerant exhibitions, workshops and science fairs in schools and public spaces. Additionally, they manage the Science Channel TV, 24 hours in the air, while keeping science columns in radio, websites and newspapers. Through these media, scientific innovation is sent to various regions of our country. Another important

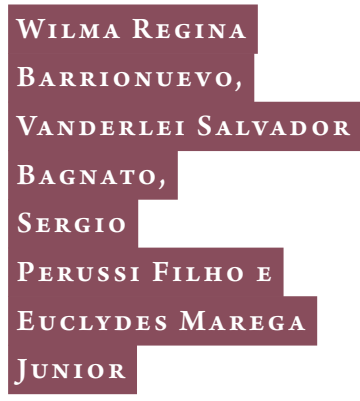

Universidade de São Paulo. Instituto de Física de São Carlos, São Paulo, Brasil 
activity is the organization of the Physics Olympiad and Physics Olympiad in Public Schools, which counted together with the provision of 863.402 students in the first phase. The present work explains the general activities of diffusion of the Group of Optics, especially the training of teachers and monitor students. In their testimonies monitors cite as benefits of projects their scientific knowledge expansion, as well as significant improvement in the ability of public speaking and ability to organize events and to respond to unforeseen situations. We hope that such actions will expand the field of possibilities that these young people have in the market job, and grant them with a more effective and positive attitude to the many challenges of life.

Keywords: Sciences Dissemination. Exhibition. Olympiad of Physics.

\section{INTRODUÇÃO}

Apesar do amplo esforço demonstrado por órgãos governamentais e por educadores em melhorar o nível de ensino e aprendizado em nosso país, os resultados têm sido morosos em um território de tão grande extensão. E o que nós, dentro de uma universidade de renome como a USP, podemos fazer a respeito? Acreditamos que seja nossa obrigação darmos uma contribuição nesse sentido, especialmente para o nosso grupo, já empenhado há tantos anos em divulgar Ciência à sociedade.

Um dos grandes problemas enfrentados pelas escolas brasileiras é que os currículos tradicionais não conseguem acompanhar o ritmo das mudanças que ocorrem na sociedade nesse mundo globalizado. Salas de informática têm sido implantadas, mas ainda faltam professores [4]. Além disso, dificilmente encontramos laboratórios científicos [2]. Tal retrato não permite que os alunos visualizem de forma prática $o$ que é ensinado em sala de aula, no esquema tradicional de giz e lousa. Assim, esses alunos, na maioria das escolas, passam pelos ensinos Fundamental e Médio, sem terem experimentado a verdadeira emoção de fazer Ciência por eles mesmos [3,5]. De forma ideal tal emoção pode ser despertada, agregando-se conteúdo e motivação às aulas expositivas, assim como às aulas práticas.

O problema da falta de atividades práticas tem sido exemplarmente amenizado nas escolas técnicas, que vêm melhorando progressivamente seu nível de ensino prático [4]. O ideal, no entanto, é que se reúnam a profundidade de um ensino teórico com a destreza e o despertar da curiosidade e da solução de problemas, proporcionado pela experiência prática [6]. Além disso, é preciso descentralizar e disponibilizar ciências também para os alunos que vivem nas cidades do interior e vilarejos, de modo que possam experimentar a emoção da Ciência. Para isso, precisamos inovar!

O Grupo de Óptica, do Instituto de Física de São Carlos da Universidade de São Paulo (IFSC-USP) é uma referência nacional e mundial, em pesquisa e desenvolvimento tecnológico. A excelência das atividades realizadas pelo grupo permitiu a origem de dois centros de excelência nas áreas de Óptica e Fotônica: o CEPOF, Centro de Excelência em Óptica e Fotônica, criado e financiado pela FAPESP, e o INOF, Instituto Nacional de Óptica e Fotônica, criado pelo CNPq/FINEP.

A equipe de difusão científica do CEPOF/INOF vem desenvolvendo inúmeras 
atividades de difusão científica desde 2001, principalmente por meio de workshops, mini-cursos, exposição itinerante de ciências, feiras de ciências em shopping centers e em outros locais públicos da cidade [1]. De forma relevante e marcante, o CEPOF e o INOF contam, ainda, com um Canal de TV (Canal 20, da rede NET) e programas de rádio, onde são veiculados programas científicos, tecnológicos e de inovação para toda a região de São Carlos. O sucesso alcançado por tais atividades foi reconhecido com o Prêmio José Reis $(\mathrm{CNPq})$ para o coordenador da equipe. Dentre as atividades desenvolvidas pelo grupo em escolas destacam-se a exposição itinerante A USP vai à sua Escola, o programa de TV Fala Jovem e as feiras de ciências. Outra atividade importante do grupo refere-se à organização da Olimpíada Brasileira de Física (OBF) e da Olimpíada Brasileira de Física das Escolas Públicas (OBFEP), que envolvem anualmente milhares de estudantes e professores. Além disso, no mesmo ano, alunos finalistas da OBF 2012 receberam suas medalhas das mãos de cinco ganhadores de Prêmios Nobel, em evento organizado no Instituto de Física de São Carlos, na USP.

A exposição itinerante A USP vai à sua Escola consiste em levar ciência até estudantes da rede pública de ensino, por meio de kits educacionais interativos e de filmes, apresentados às escolas de modo atraente, por monitores da USP e das próprias escolas. As principais áreas abordadas são as de Física, principalmente Óptica, e de Biologia. Os painéis de Óptica incluem explicações e animações sobre cores, lasers, ilusões de óptica, hologramas, mundo atômico e visão em $3 \mathrm{D}$. Os de Biologia trazem explicações sobre células, genoma, células-tronco, nanotecnologia e corpo humano. Os monitores do programa são alunos da USP e professores e estudantes das próprias escolas públicas, que são treinados na USP. O grupo é bastante unido em torno do ideal de auxiliar na melhoria do nível de ensino, principalmente do ensino público. A exposição destina-se a despertar a Ciência em estudantes e, também em cidadãos comuns, que demonstram grande interesse pelas explicações dadas pelos monitores.

O programa de TV Fala Jovem também atrai um grande número de estudantes, de escolas públicas, que aprendem a produzir programas televisivos em todas as suas etapas: ideação, elaboração de script, filmagem, entrevistas e edição. Já as feiras de ciências, envolvem estudantes, professores, e delegacias de ensino. Na feira científica realizada em 2012 o melhor expositor foi premiado com uma viagem aos museus científicos e tecnológicos de Washington D.C., nos Estados Unidos. Os demais alunos premiados receberam bolsa de Iniciação Científica do CNPq, para que desenvolvessem projetos científicos e os divulgassem em suas escolas, de modo a tornarem-se agentes divulgadores de ciências junto aos seus colegas. No ano de 2013 o grupo levou, ainda, uma feira de ciências de nível nacional para Novo Airão, um pequeno município próximo a Manaus, na Amazônia. O evento contou com a participação de centenas de estudantes, professores e comunidade circunvizinha.

Espera-se, por meio das atividades de difusão científica do Grupo de Óptica, que os estudantes e professores envolvidos possam entrar em contato com aspectos modernos e avançados da investigação científica. Este é um importante passo dado no sentido de auxiliar na difusão equitativa do conhecimento e na aquisição, por parte dos estudantes, de múltiplas habilidades e competências. Espera-se que tais ações venham a ampliar o campo de possibilidades que esses jovens terão no mercado de 
trabalho, além de conceder-lhes uma atitude mais eficaz e positiva frente aos inúmeros desafios da vida.

\section{METODOLOGIA}

\section{Público-alvo}

Os trabalhos de difusão científica do Grupo de Óptica têm como público alvo, estudantes e professores, principalmente de escolas públicas e a população em geral, que visita regularmente as exposições, além de assistir diariamente aos programas televisivos.

\section{Estabelecimento de Indicadores para Acompanhamento do Projeto}

Para o acompanhamento do desenvolvimento deste projeto foram estabelecidos inicialmente alguns indicadores para avaliar e ajustar as ações de forma eficiente e dinâmica. As avaliações foram realizadas por meio de reuniões periódicas com a equipe e por meio de pesquisas, realizadas nas escolas e exposições públicas, de modo a se avaliar os seguintes fatores:

a) Grau de satisfação de estudantes, professores e público em geral, em relação aos painéis da exposição itinerante. Aspectos analisados: transmissão clara do conteúdo científico, visual agradável e grau de interatividade dos painéis (por meio de botões, vídeos, luzes, cores e efeitos especiais);

b) Grau de satisfação quanto à explicação dos monitores;

c) Grau de satisfação quanto a cada tema abordado pelo museu fixo e itinerante;

d) Entendimento geral do conteúdo das diferentes áreas temáticas;

e) Quantidade de participantes dos eventos;

f) Sugestões de melhorias e críticas.

Os indicadores acima foram avaliados constantemente pelos coordenadores e monitores do projeto e os procedimentos e temas foram reajustados de forma ininterrupta, para melhoria da qualidade da exposição.

\section{Detalhamento das Ações}

\section{Ação 1 - Exposição itinerante A USP vai à sua Escola}

A elaboração da exposição itinerante envolveu as seguintes etapas:

1. Ideação da exposição e de seu conteúdo, por parte de pesquisadores, alunos e técnicos do Grupo de Óptica;

2. Confecção dos painéis educativos interativos na oficina mecânica e eletrônica do 
Grupo de Óptica;

3. Estabelecimento de logística para visitação às escolas, compreendendo as seguintes etapas:

a) Contato com as Secretarias de Educação Municipal e Estadual;

b) Contato com as escolas para agendamento da exposição e indicação de monitores/estudantes por parte da escola;

c) Seleção de monitores, estudantes da USP, para auxiliarem na exposição;

d) Treinamento prévio de professores e monitores da USP e das escolas públicas visitadas, sobre o conteúdo científico e a logística da exposição;

e) Transporte da exposição em veículo (van) destinado a este fim;

f) Realização da exposição;

g) Avaliação da exposição, por meio de pesquisas em salas de aula;

h) Acompanhamento dos monitores, por meio de reunião, onde os mesmos foram ouvidos e falaram de suas experiências com a exposição, deram sugestões e discorreram sobre seus planos futuros de ação profissional e pessoal.

\section{Ação 2 - Projeto Fala Jovem}

Etapas de realização:

1. Seleção de bolsistas da USP para auxiliarem no monitoramento do projeto;

2. Seleção de alunos de escolas públicas para participarem do projeto;

3. Treinamento dos monitores e alunos, envolvendo o seguinte aprendizado:

" Noções sobre o funcionamento do ambiente televisivo;

" Estabelecimento de metas, seleção de temas e elaboração de script dos programas de TV a serem elaborados;

" Treinamento dos estudantes em habilidade oral e em desinibição, para a execução de entrevistas e de programas de TV de nível científico;

"Treinamento dos estudantes em edição dos programas televisivos;

॥ Exibição dos programas na TV Ciência - Canal 20 da NET de São Carlos.

Ação 3 - Produção de programas televisivos, feiras de ciências, treinamento de professores e monitores, realização da Olimpíada Brasileira de Física e realização da Olimpíada Brasileira de Física das Escolas Públicas

1. Programas de TV: os programas televisivos foram gravados em nosso próprio estúdio. A programação de 24 horas diárias contém programas científicos, aulas, palestras, música e programas de entrevistas voltadas para a área de Ciência e inovação empresarial;

2. Feiras de ciências de nível estadual e nacional: durante o processo de divulgação da feira estadual foi feito contato com as delegacias de ensino de todo o Estado de São Paulo. Além disso, a equipe de difusão científica visitou centenas de escolas 
e colocou todas as explicações em texto e vídeo no site, de forma detalhada. Já a feira de nível nacional, foi realizada em um vilarejo da Amazônia. As prefeituras da região contrataram vários ônibus, o que permitiu a participação de milhares de estudantes, professores e cidadãos amazonenses na feira. A exposição foi levada pela equipe por avião, em caixas e malas, e por terra em dois automóveis (vans);

3. Treinamento de professores e monitores: os treinamentos são agendados e realizados na USP. A exposição é montada no saguão do Instituto de Física de São Carlos e os professores e monitores de diferentes cidades assistem a filmes e palestras e recebem explicações de todos os painéis educativos, para que possam interagir com os alunos em sala de aula, durante e após a exibição da exposição em suas escolas;

4. Olimpíada Brasileira de Física: destinado a estudantes da oitava série do Ensino Fundamental ao terceiro ano do Ensino Médio, com o objetivo de despertar o interesse pela Física e incentivar os estudantes a seguirem carreiras científico-tecnológicas. Além disso, visa prepará-los para as Olimpíadas Internacionais de Física como forma de comparar o nosso ensino com o de outros países.

\section{Ação 4 - Avaliação das exposições itinerantes}

As exposições itinerantes foram avaliadas por meio de questionários impressos, aplicados pelos monitores em sala de aula e nas salas dos professores, logo após os alunos passarem pela exposição.

\section{RESULTADOS}

Avaliação do Grau de Satisfação de Estudantes, Professores e Monitores, em Relação aos Projetos A USP vai à sua Escola e Fala Jovem

O grau de satisfação de estudantes, professores e monitores, foi verificado por meio de questionários exemplificados na Tabela 1.

Tabela 1 - Exemplos das perguntas efetuadas em pesquisa realizada com estudantes, monitores e professores envolvidos com o projeto.

PERGUNTAS FEITAS PARA OS ALUNOS

$\begin{array}{ll} & \text { a. ( ) uma luz espalhada e forte; b. ( ) uma luz } \\ \text { condensada, com capacidade para cortar tecidos } \\ \text { biológicos e placas de metal; c. ( ) uma luz espalhada e } \\ \text { fraca, utilizada somente para iluminação de baladas. }\end{array}$



em 46 pares de cromossomos; c. ( ) não contém cromossomos; d. ( ) encontra-se todo fora do núcleo da célula.

Em termos de conteúdo científico, qual conceito você daria para esta exposição?

a. ( ) ótimo; b. ( ) bom; c. ( ) regular; d. ( ) ruim; e. ( ) péssima

Você considera importante esse tipo de exposição para a sua escola?

a. ( ) sim; b. ( ) não; c. ( ) tanto faz.

PERGUNTAS FEITAS PARA OS MONITORES

(ESTUDANTES DA USP E DAS ESCOLAS PÚBLICAS):

a. Qual a importância deste projeto para você? O que acrescentou ao seu aprendizado?

b. $\bigcirc$ que você faria diferente?

PERGUNTAS FEITAS AOS PROFESSORES:

a. Você considera que esta exposição foi importante para a sua escola? Por quê?

b. Quais sugestões você nos daria para as próximas exposições?

Por meio dos questionários realizados em sala de aula pelos monitores do projeto foram obtidas as seguintes respostas:

a) Quanto à compreensão do conteúdo científico mostrado nos painéis educativos e explicado pelos monitores: os estudantes mostraram uma média de acertos de $68 \%$, o que foi considerado satisfatório pela equipe, considerando que os alunos não estavam inicialmente muito familiarizados com os temas abordados sobre Física, Química e Biotecnologia.

b) Quanto à importância da continuidade da exposição para a escola: 100\% dos professores e $92 \%$ dos alunos sugeriram a continuidade da exposição.

c) Quanto à clareza de explicação: 87\% dos alunos disseram que as explicações dadas pelos monitores eram claras e interessantes.

d) Quanto às perguntas feitas aos monitores, eles citam como benefícios dos projetos a ampliação de seus conhecimentos científicos, além de sensível melhoria na capacidade de oratória em público e da capacidade de organizar eventos e de responder às situações imprevistas. Por outro lado, os monitores criticaram o peso dos painéis e a falta de interesse de alguns alunos que assistiram às explicações. 
1. Produção de 112 programas científicos, os quais foram veiculados na mídia: TV Ciência, rádio, jornais e internet. Tais programas foram gravados em DVDs e utilizados intensivamente como meios eficazes para atingir o maior número possível de pessoas para o ensino de ciências;

2. Treinamento de 32 estudantes para produzirem os programas televisivos Fala Jovem em todas as suas etapas: ideação, elaboração de script, apresentação de programas e edição dos mesmos;

3. Realização de oito exposições científicas e tecnológicas - Semóptica: no Shopping Center Iguatemi São Carlos, no Museu da Ciência de São Carlos professor Mário Tolentino e em escolas, levando ao público em geral conhecimento científico;

4. Visitação de 22 escolas públicas do Estado de São Paulo, por meio da exposição itinerante A USP vai àz sua Escola (Figura 1);

Figura 1 - Exposições científicas: (a) e (b) no Shopping Center Iguatemi São Carlos, (c) na Escola Estadual Jesuíno de Arruda e (d) no Museu de Ciências da cidade de São

Carlos.
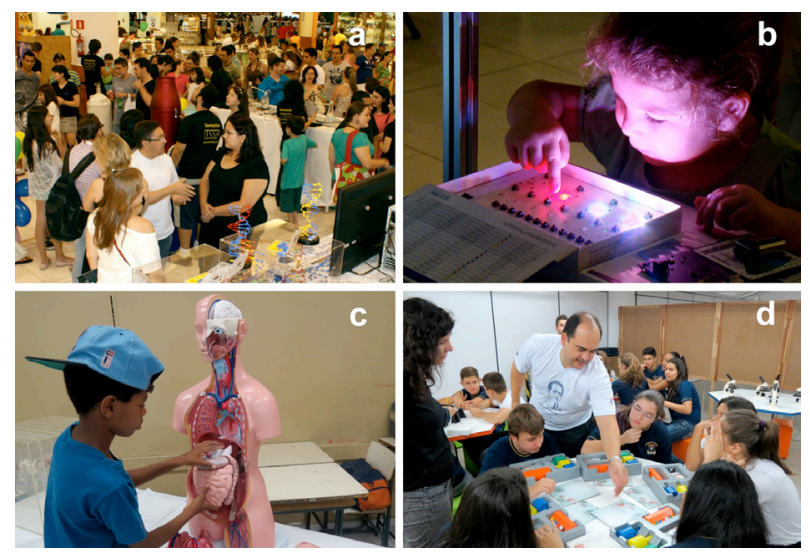

5. Aplicação de 68 cursos e aulas-show em vários temas da Ciência em especial da Física e da Biologia. Utilização da infraestrutura universitária para auxiliar na complementação do ensino de Ciência dos ensinos Médio e Fundamental, por meio de dezenas de treinamentos;

6. Realização de seis treinamentos amplos, que incluíram professores e estudantes da região e de outros estados. Tais professores agiram como difusores e multiplicadores do conhecimento e foram essenciais para o sucesso do projeto;

7. Realização de quatro workshops, denominados Caminhos da Inovação;

8. Publicação de dois livros (anos 2012 e 2013) nas áreas de Difusão Científica e Inovação Tecnológica e Empresarial [1, 6];

9. Colaboração na Realização da Olimpíada Brasileira de Física OBF, organizada pela Sociedade Brasileira de Física (SBF): No ano de 2013 foram inscritos 444.238 alunos, dos quais 1067 receberam medalhas. Após realizada a terceira fase, os melhores alunos receberam medalhas e os primeiros colocados participaram de duas competições internacionais: 
a) Olimpíada Iberoamericana de Física (OIbF), onde obtiveram 4 medalhas (2 de ouro e 2 de prata), em Santo Domingo, na República Dominicana; e

b) Olimpíadas Internacionais de Física (IphO), que aconteceu em Copenhague, na Dinamarca, onde obtiveram 5 medalhas ( 1 de prata e 4 de bronze).

10. Colaboração na Realização da Olimpíada Brasileira de Física das Escolas Públicas (OBFEP), organizada pela Sociedade Brasileira de Física (SBF): no ano de 2013 foram inscritos 419.164 alunos.

Tabela 2 - Abrangência e impacto do projeto em um ano de atividade.

ATIVIDADES DESENVOLVIDAS

Programas da TV Ciência - Canal 20 da NET

(audiência diária, estimada pela NET - São

Carlos)
NÚMERO DE PARTICIPANTES

120.000

Exposição itinerante, cursos e treinamentos em

escolas, nas cidades de São Carlos e de São

Paulo

37.400
8.400

Exposição itinerante shopping, Museu de

Ciências

5.300

Feiras de Ciências

40.000

Sites, colunas de rádio, colunas de jornal (estimado)

310.966

Olimpíada Brasileira de Física - OBF*

293.415

Olimpíada Brasileira de Física nas Escolas

Públicas - OBFEP*

$\begin{array}{ll}\text { Total } & 815.481\end{array}$

* Foram inscritos 444.238 alunos na OBF e 419.164 alunos na OBFEP. Para sermos mais realistas, consideramos $30 \%$ de ausência na execução das provas da primeira fase. 


\section{CONCLUSÃO}

Fazer com que a emoção da Ciência e o conhecimento científico e tecnológico fiquem disponíveis para os alunos certamente constitui-se em grande desafio para aqueles interessados em dedicar parte do seu tempo para difundir a Ciência como uma alternativa para melhorar a sociedade. A disseminação de conhecimento científico é fundamental para a crítica e envolvimento consciente da sociedade nos temas da Ciência e Tecnologia, visto que o desenvolvimento nessas áreas leva à transformação da vida das pessoas e tende a gerar talentos especiais. Estudantes que experimentam com Ciências, comprovadamente são mentes que se alteram para sempre. O valor da Ciência na mente dos jovens muda seu comportamento e seu desejo de contribuir, visto que o conhecimento sempre vence a ignorância. Precisamos ensinar Ciências para termos bons cidadãos, ainda que não necessariamente cientistas. Os resultados verificados neste trabalho mostram que mais de 800 mil pessoas, estudantes, professores e público em geral têm acesso anualmente às amplas atividades desenvolvidas pelo Grupo de Óptica. Esperamos, assim, possibilitar que os alunos e professores envolvidos e demais cidadãos sintam-se incluídos socialmente nas atividades desenvolvidas pela USP e que especialmente os alunos de escolas públicas tenham condições de aprender Ciência e Tecnologia, de modo que possam ter melhores chances no mercado de trabalho e também, que possam contribuir para o desenvolvimento científico e tecnológico do país.

\section{REFERÊNCIAS}

[1] BAGNATO, V. S.; LONGO, E.; BARRIONUEVO, W. R. Cooperação em inovações tecnológicas entre Brasil e Itália. $1^{\mathrm{a}}$ ed. São Carlos: Editora Compacta, 2013.

[2] BUENO, W. C. Jornalismo científico no Brasil: Os compromissos de uma prática dependente. 1984, 364 f. Tese (Doutorado) - USP, ECA, São Paulo, 1984.

[3] CORACINI, M.J. Desconstruindo o discurso da divulgação: Questões do significado e da autoria. In: ARROJO, R. (Org.). O signo desconstruído: Implicações para a tradução, a leitura e o ensino. Campinas: Pontes, pp. 81-86, 1992.

[4] GOUVÊA, G. A divulgação científica para crianças: $O$ caso da Ciência Hoje das crianças. 2000, 305 f. Tese (Doutorado) - CCS, UFRJ, 2000.

[5] MOREIRA, I. C. A inclusão social e a popularização da ciência e tecnologia no Brasil. Inclusão Social, Brasília, v. 1, n. 2, pp. 11-16, abr. - set. 2006.

[6] PERUSSI FILHO, S.; BAGNATO, V. S.; BARRIONUEVO, W. R. Caminhos da Inovação. A visão de cientistas, educadores, empreendedores e agentes de inovação. $1^{\mathrm{a}}$ ed. São Carlos: Editora Compacta, 2012. 


\section{AGRADECIMENTOS}

Ao CNPq, à Fapesp e ao Instituto de Física de São Carlos da Universidade de São Paulo (IFSC-USP) pelo suporte e apoio obtido durante a execução do presente trabalho.

WILMA REGINA BARRIONU V Vo coordenadora de Difusão Científica do Grupo de Óptica do Instituto de Física de São Carlos da Universidade de São Paulo (IFSC-USP) - e-mail: wilma@ifsc.usp.br

VANDERLEI SAlvador BAgnato coordenador do Centro de Pesquisas em Óptica e Fotônica (CEPOF) e professor titular do Instituto de Física de São Carlos da Universidade de São Paulo (IFSC-USP) - e-mail: vander@ifsc.usp.br

SERGIO PERUSSI FILHO professor do Centro Universitário Paulista (UNICEP) e professor colaboradorda Universidade de São Paulo (IFSC-USP) - e-mail: sergioperussi@gmail.com

euclydes marega junior coordenador de Difusão Científica do Centro de Pesquisas em Óptica e Fotônica (CEPOF) e professor titular do Instituto de Física de São Carlos da Universidade de São Paulo (IFSC-USP) - e-mail: euclydes@ifsc.usp.br 